\title{
DIAGNOSTICS OF AURORAL OVAL BOUNDARIES ON THE BASIS OF THE MAGNETOGRAM INVERSION TECHNIQUE
}

\author{
S.B. Lunyushkin \\ Institute of Solar-Terrestrial Physics SB RAS, \\ Irkutsk, Russia, lunyushkin@iszf.irk.ru
}

\author{
Yu.V. Penskikh \\ Institute of Solar-Terrestrial Physics SB RAS, \\ Irkutsk,Russia,penskikh@iszf.irk.ru
}

\begin{abstract}
It is shown that the convection reversal boundary is a fundamental parameter of the magnetosphere-ionosphere coupling, which determines a strong analogy between the electrostatic potential of the ionosphere and the equivalent current function in the dipole geomagnetic field approximation and the uniform ionospheric conductance. We have developed a new groundbased method for automatically diagnosing boundaries of the auroral oval using output data obtained with the magnetogram inversion technique (MIT). Using maps of the current function and field-aligned currents, calculated at the first stage of MIT with uniform ionospheric conductance, we determine the convection reversal boundary, polar cap boundary, equatorial boundary of the auroral oval, and line of maximum density of auroral electrojets. These parameters have previously been determined by a visual-manual method: analyzing maps of field-aligned and equivalent currents on the monitor screen and carrying out predetermined boundaries with
\end{abstract}

\section{INTRODUCTION}

The concept of auroral oval was introduced into magnetospheric physics fifty years ago [Feldstein, Starkov, 1967; Akasofu, 1968; Feldstein, 1969] and was based on the analysis of the configuration of the region of distribution of arcs and strips of auroras generated by highenergy $(>1 \mathrm{keV})$ particle fluxes precipitating into the high-latitude ionosphere. The history of polar research, led to the discovery and determination of the auroral oval configuration, is well described in recent reviews [Lazutin, 2015; Feldstein, 2016].

In the topology of the magnetosphere, the auroral oval in each hemisphere is an ionospheric projection of the plasma sheet and has polar and equatorial boundaries at which there is a sharp decrease in energy and flux of electrons and ions precipitating from the plasma sheet, which produce auroras. The polar boundary of the auroral oval coincides with the polar cap boundary, which is an ionospheric projection of the magnetotail lobe. In the open magnetosphere model [Dungey, 1961], magnetic field lines of magnetotail lobes are connected with the interplanetary magnetic field (IMF), and the amount of open magnetic flux determines the electromagnetic energy transfer from the solar wind to the magnetosphere. The polar cap expansion (contraction) is equivalent to an increase (decrease) in the magnetic flux through the polar cap and, accordingly, reflects the dynamics of magnetic energy accumulation (release) in the magnetotail — the most important parameter that controls the growth phase and the onset of substorm the mouse - this took a very long time (weeks and months). The comparison between manually and automatically obtained boundaries has shown that the correlation coefficient between the two boundaries is, on average, 0.85 , and the root-mean-square deviation does not exceed $2^{\circ}$ in latitude. By providing an adequate accuracy for the boundary determination, the automatic method reduces the time for map processing by a factor of 2-3 (to minutes and hours), releasing a researcher from laborious visual work. The new method is implemented as one of the important modules in the updated MIT software.

Keywords: ionospheric convection, equivalent current function, auroral oval, polar cap, field-aligned currents, convection reversal boundary.

expansion phase [Russell, McPherron, 1973; Akasofu, 1977; Milan et al., 2007; Shukhtina et al., 2016]. In the closed magnetosphere model [Axford, Hines, 1961; Heikkila, 2011], polar caps are also topologically related to the respective magnetotail lobes; however, the magnetic field lines in them are closed and stretched far antisunward. Polar caps rarely exhibit auroras, and satellites generally record weak fluxes of low-energy ( $<100 \mathrm{eV}$ ) electrons scattered from magnetotail lobes [Winningham, Heikkila, 1974; Haaland et al., 2017]. To the equatorial boundary of the auroral oval on the midnight side corresponds the inner edge of the plasma sheet, the distance to which decreases slightly with increasing magnetospheric convection during the substorm growth phase and sharply decreases during the substorm expansion phase due to magnetic field dipolarization and plasma injection earthward from the reconnection region in the midtail $(15 \div 20) R_{\mathrm{E}}$ [Akasofu, 1977]. The auroral oval width determined by the two boundaries also changes, narrowing during the growth phase, which corresponds to an increase in the magnetic flux in the tail lobe and to a thinning of the plasma sheet, and expanding rapidly during the substorm expansion phase.

Thus, the study of the auroral oval dynamics and boundaries give very valuable information about the topology of the magnetosphere and its dynamics during geomagnetic storms and substorms. Currently, the main methods for direct observation of the auroral oval and determination of its boundaries are satellite measure- 
ments of parameters of particles precipitating into the polar ionosphere and global satellite images of the auroral oval.

The method for determining auroral oval boundaries from satellite measurements of energy spectrum parameters and pitch-angle distribution of precipitating electrons and ions has come into widespread use under the long-term program (DMSP) of launches of satellites with polar orbits at $\sim 800 \mathrm{~km}$ [Makita et al., 1983, 1985]. With sufficiently high reliability, this method has, however, a major drawback - the measurements are not global and do not provide a full instantaneous picture of the auroral oval because consecutive satellite passages are separated by an interval of $\sim 100 \mathrm{~min}$. Further development of the method led to the creation of the wellknown auroral oval model OVATION [Sotirelis, Newell, 2000; Newell et al., 2014]. Among the existing statistical models, which are also based on data from DMSP satellites, particularly noteworthy is the model [Gussenhoven et al., 1983] for the equatorial boundary of the auroral oval on the midnight meridian and the interactive model APM [Vorobjev et al., 2013].

The global method for diagnostics of the auroral oval is based on its images from the IMAGE satellite, which are obtained in ultraviolet every 2 min with Wideband Imaging Cameras (WIC) and specially developed methods for processing such images [Boakes et al., 2008; Hubert et al., 2010; Longden et al., 2010; Milan et al., 2010]. To increase the accuracy in determining auroral oval boundaries, a special method has been developed for estimating the intensity of auroras and searching for thresholds [Longden et al., 2010], which is automated to process a large number of images and to create a database containing more than million values of auroral oval boundaries. By comparing optical boundaries of the polar cap with DMSP data on precipitating particles, Boakes et al. [2008] have established that two independent methods give similar results (within $\pm 2^{\circ}$ ), hence the polar boundary of the auroral brightness is a good indicator of the polar cap boundary.

In view of the above, the development of new methods for diagnostics of auroral oval boundaries is one of the urgent problems of magnetospheric physics. In the magnetogram inversion technique (MIT) developed at ISTP SB RAS [Bazarzhapov et al., 1979; Mishin, 1990], determining auroral oval boundaries is a mandatory procedure. MIT calculates 2D maps of distributions of equivalent currents, electric potential, horizontal and field-aligned currents (FACs) in the polar ionosphere from ground geomagnetic measurements at the worldwide network of stations. An essential part of MIT is the original dynamic model of conductance of the polar ionosphere caused by precipitating electrons and protons [Mishin et al., 1986; Shirapov et al., 2000]. The required input parameters of the model are the auroral oval boundaries determined from FAC maps, calculated at the first stage of MIT in the approximation of uniform conductance. Three parameters are found: polar R0 and equatorial R2 auroral oval boundaries, as well as R1 - the line of maximum density of auroral electrojets. The polar cap boundary R0 corresponds to the high-latitude boundary of large-scale FACs of IijimaPotemra Region 1; and the equatorial boundary R2, to the low-latitude boundary of Region 2 FAC. The latitude of maximum density of auroral electrojets $\mathrm{R} 1$ coincides with the boundary between Regions 1 and 2. In the MIT software package and in this paper, letter $\mathrm{R}$ in the agreed notation denotes the radius of the southern boundary of the corresponding FAC Region. The correspondence of the FAC areas of both Regions 1 and 2 with the auroral oval was noted already in the pioneer paper by Iijima, Potemra [1978] and was subsequently confirmed by a number of simultaneous observations of precipitating particles, auroras, and field-aligned currents.

The R0, R1, and R2 auroral oval boundaries have yet, unfortunately, been identified in MIT manually, by visually analyzing maps of field-aligned and equivalent currents and by drawing boundaries with a mouse in a special program on the screen. This map processing method takes a lot of time (weeks or even months), hence the need to develop an automatic method of determining the main auroral oval boundaries, which would replace the human operator, be fast and sufficiently accurate, and be as good as the visual-manual method.

The purpose of this paper is to develop and automate a new ground-based method for diagnostics of auroral oval boundaries based on MIT. The basic theoretical principles of the method are formulated in Section 1. Section 2 describes the algorithm for implementing the automatic method and compares it with the manual method. Section 3 discusses some fundamental issues. The main results are presented in Conclusion.

\section{BASIC PRINCIPLES OF THE METHOD}

In Introduction, we have presented two main methods of satellite diagnostics of the polar cap boundary: based on data on spectral parameters of precipitating particles and based on global auroral oval images. The third method, which identifies the polar cap boundary with the ionospheric convection reversal boundary, was actually initiated by the advent of direct measurements of electric fields on board the OGO-6 satellite along its dawn-dusk trajectory [Heppner, 1972]. Then, this method was developed in many papers dealing with the ionospheric convection calculated from drift velocity measurements on board DMSP satellites [Troshichev et al., 1996; Chen et al., 2015] and Super Dual Auroral Radar Network (SuperDARN) [Bristow, Spaleta, 2013; Koustov, Fiori, 2016]. Notice that the ionospheric convection reversal boundary is slightly to the south of the polar cap - at a distance of $\sim 1^{\circ}$ near the noon and at $2^{\circ}-3^{\circ}$ near the dawn-dusk meridian, which corresponds to the width of the low-latitude boundary layer of the magnetosphere [Drake et al., 2009].

The magnetosphere-ionosphere convection reversal boundary is the fundamental principle of the new method for diagnostics of auroral oval boundaries.

\subsection{Convection reversal boundary}

The fundamental natural phenomenon in Earth's magnetosphere is the continuous magnetospheric convection consisting of two large-scale vortices. These 
vortices are formed by the plasma that moves antisunward in boundary layers and magnetotail lobes, and drifts in the reverse direction earthward in the plasma sheet. To the closed and open magnetospheric models (see Introduction) correspond two different physical mechanisms of generation of the magnetospheric convection - quasi-viscous interaction between the solar wind and the magnetosphere in the low-latitude boundary layer [Axford, Hines, 1961] and IMF reconnection with the geomagnetic field at the dayside magnetopause with subsequent formation of open magnetotail lobes [Dungey, 1961]. The former mechanism is permanent and largely controlled by the solar wind velocity and density. The operation of the latter mechanism depends on the IMF hour angle, where the main role is played by its southward component. The large-scale magnetosphereionosphere convection exists permanently because the simultaneous operation of the two physical mechanisms provides continuous conversion of the solar wind kinetic energy into electric energy in the boundary layers of the magnetosphere on the principle of the plasma MHD generator.

Figure 1 illustrates a mechanism of generation of electromotive force (EMF) in the low-latitude boundary layer in the closed magnetosphere model [Heikkila, 2011]. This mechanism gives rise to a dawn-dusk electric field across the tail and eventually leads to the formation of a large-scale two-vortex system of magnetospheric convection. The existence of the boundary layer (BL) with the characteristic width $d$ and antisunward plasma is provided by the mechanism of quasi-viscous interaction between the solar wind and the magnetosphere. Since plasma moves with a velocity $\mathbf{V}=\mathbf{V}_{x}$ in $\mathrm{BL}$ across the magnetic field $\mathbf{B}=\mathbf{B}_{z}$, protons and electrons under the action of the Lorentz force $\mathbf{F}_{y}= \pm e \mathbf{V}_{x} \times \mathbf{B}_{z}$ deflect accordingly in such an MHD channel to its inner and outer boundaries, thus producing polarization electric fields $E_{\mathrm{BL}}$ and respective EMF $U_{ \pm}=E_{\mathrm{BL}} d$ in BL on the dawn and dusk flanks of the magnetosphere. The plasma velocity profile across the tail, indicated by the dashed line in Figure 1, shows that the plasma velocity $V$ in BL decreases with respect to the solar wind velocity $V_{\mathrm{sw}}$ on the outer boundary of the layer to $V=0$ on its inner boundary. Then, the plasma moves earthward with electric drift velocity increasing toward the center of the plasma sheet: $V_{\mathrm{E}}=E_{\mathrm{M}} / B_{z}$, where $E_{\mathrm{M}}=\left(U_{+}-U_{-}\right) /\left(2 R_{\mathrm{T}}\right)$ is the dawn-dusk electric field across the cylindrical tail with a radius $R_{\mathrm{T}} \approx 25 R_{\mathrm{E}}$.

Thus, the BL inner boundary is the magnetospheric convection reversal boundary (RB) corresponding to outer plates of two (dawn and dusk) MHD generators, whose voltage is $U_{+}$and $U_{-}$. The ionosphere always has a non-zero conductivity (or conductance, the term used for the altitude-integrated conductivity), and fieldaligned conductivity is infinite. A FAC pair $\left(I_{1}\right)$ therefore occurs which connects boundary layer generators to a load (ionosphere), forming a single electric circuit. At the same time, the potentials $U_{+}$and $U_{-}$associated with $\mathrm{RB}$ in the magnetosphere are projected unaltered

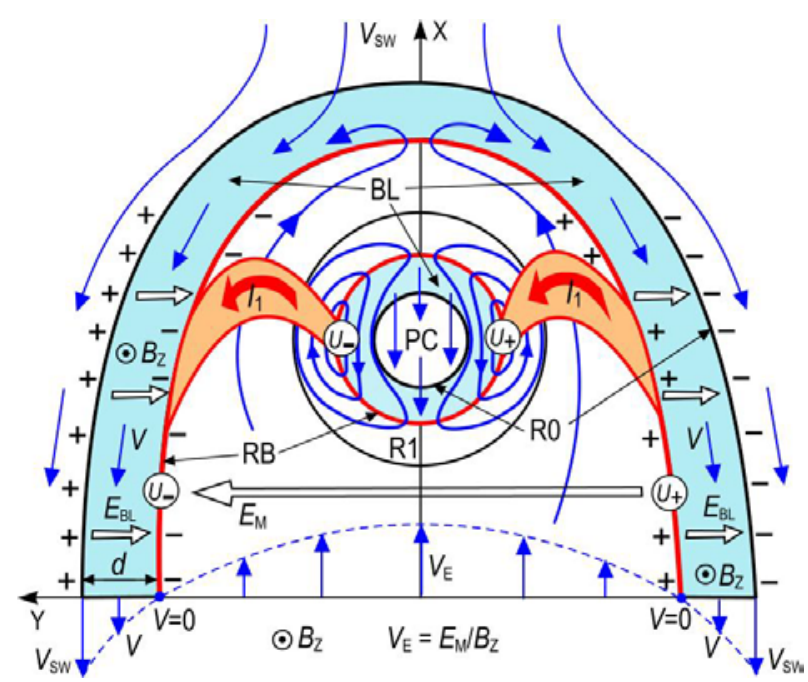

Figure 1. Scheme of generation of a large-scale twovortex system of magnetospheric-ionospheric convection in the closed magnetosphere. Notations: the X-axis - to the Sun, the $\mathrm{Y}$-axis - from dawn to dusk; R0 is the auroral oval polar boundary (the boundary of the polar cap PC); RB (red line) is the convection reversal boundary; R1 is the line of maximum density of auroral electrojets; BL (turquoise fill) is the lowlatitude boundary layer of width $d$; straight, curved, and closed blue lines with arrows show plasma flows (convection); $V_{\mathrm{sw}}$ is the solar wind velocity; $V$ is the plasma velocity in the $\mathrm{BL}$ channel; $V_{\mathrm{E}}$ is the earthward electric drift velocity in the plasma sheet; $B_{z}$ is the vertical magnetic field component in the tail; signs “+” (protons) and "-” (electrons) indicate polarization in the MHD channel of BL; thick hollow arrows mark the polarization electric field $E_{\mathrm{BL}}$ in the $\mathrm{BL}$ channel and the dawn-dusk electric field $E_{\mathrm{M}}$ in the plasma sheet; $U_{+}$and $U_{-}$ are the electric potentials transmitted into the ionosphere by FACs of Iijima-Potemra Region $1\left(I_{1}\right)$; the dotted blue line is the profile of the change in the $x$ component of plasma velocity along the $\mathrm{Y}$-axis

onto the respective RB boundary in the ionosphere (Figure 1), where they cause plasma electric drift and form a two-vortex system of ionospheric convection similar to the magnetospheric one.

Based on the above, the ionospheric convection reversal boundary $R B$ which has a clear physical meaning is accepted as a basic principle of the method for diagnostics of auroral oval boundaries. The main physical property of the RB boundary is its relationship with Region 1 FACs density maxima coinciding with extrema of electric potentials.

\subsection{Relationship between ionospheric con- vection and equivalent current function}

The second principle of the method $-2 D$ distributions of electrostatic potential and equivalent current function fully correspond to each other in the polar ionosphere in a uniform conductance approximation - is one of the exact solutions of the theoretical problem discussed in detail in the pioneer paper by Kern [1966], which stimulated the development of MIT. We show this, using Ohm's integral law for horizontal ionospheric current:

$$
\mathbf{j}=\mathbf{j}_{\mathrm{P}}+\mathbf{j}_{\mathrm{H}}=\Sigma_{\mathrm{P}} \mathbf{E}+\Sigma_{\mathrm{H}} \mathbf{B} \times \mathbf{E} / B,
$$


where $\mathbf{j}_{\mathrm{p}}, \mathbf{j}_{\mathrm{H}}$ are linear densities of horizontal ionospheric Pedersen and Hall currents obtained by integrating the current density over thickness $(90 \leq z \leq 140 \mathrm{~km}$ ) of the ionospheric current-carrying layer; $\Sigma_{\mathrm{P}}, \Sigma_{\mathrm{H}}$ are the respective integral conductances; $\mathbf{B}$ is the magnetic induction vector of the geomagnetic field; $\mathbf{E}$ is the horizontal electric field.

For the uniform conductance, to the expression of the ionospheric current as a sum of actual physical components (1) uniquely corresponds the mathematical expression as a sum of curl-free $\mathbf{j}_{\text {cf }}$ and divergence-free $\mathbf{j}_{\mathrm{df}}$ parts: $\mathbf{j}=\mathbf{j}_{\mathrm{cf}}+\mathbf{j}_{\mathrm{df}}$ (Helmholtz theorem) for which the conditions $\nabla \times \mathbf{j}_{\mathrm{cf}}=0$ and $\nabla \cdot \mathbf{j}_{\mathrm{df}}=0$ hold, where $\mathbf{j}_{\mathrm{cf}}=\mathbf{j}_{\mathrm{P}}$ and $\mathbf{j}_{\mathrm{df}}=\mathbf{j}_{\mathrm{H}}$.

The classical monograph [Chapman, Bartels, 1940] on geomagnetism as well as a number of subsequent works [Kern, 1966; Fukushima, 1976; Haines, Torta, 1994] have shown that the ground geomagnetic variations in a high-latitude region are generally caused by divergence-free Hall currents closed in the polar ionosphere, which are related to the $2 \mathrm{D}$ current function $J(\theta, \lambda)$ by the simple formula

$$
\mathbf{j}_{\mathrm{df}}=\mathbf{j}_{\mathrm{H}}=\nabla J \times \mathbf{n},
$$

where $\mathbf{n}=\mathbf{r} / r$ is a unit vector of the outer normal to the spherical layer with the radius vector $\mathbf{r}$.

The equivalent current function $J$ is a classic external solution of the inverse problem of the potential theory and is a scalar field of calculated values of $J(\theta, \lambda)$ for different points of the spherical layer of radius $r$, depicted as a system of maps of isolines of equal $J$. The equivalent Hall current flows along these isolines, the difference of the $J$ values between two isolines corresponds to the strength of the current flowing between them.

The formula for calculating the distribution of the external equivalent current function $J(\theta, \lambda)$ has the form [Chapman, Bartels, 1940; Bazarzhapov et al., 1979; Haines, Torta, 1994]

$$
J(\theta, \lambda)=-\frac{R_{\mathrm{E}}}{\mu_{0}} \sum_{n=1}^{N} \frac{2 n+1}{n+1}\left(\frac{r}{R_{\mathrm{E}}}\right)^{n} Y_{n}(\theta, \lambda),
$$

where $\theta, \lambda$ are the geomagnetic colatitude and longitude (local geomagnetic time); $\mu_{0}=4 \pi \cdot 10^{-7} \mathrm{H} / \mathrm{m}$ is the magnetic constant; $r=R_{\mathrm{E}}+h ; R_{E}=6371 \mathrm{~km}$ is the Earth radius; $h=115 \mathrm{~km}$ is the reduced height of the ionospheric current-carrying layer; the spherical harmonic $Y_{n}(\theta, \lambda)$ is described by the formula

$$
Y_{n}(\theta, \lambda)=\sum_{m=0}^{n}\left(E_{n}^{m} \cos m \lambda+e_{n}^{m} \sin m \lambda\right) P_{n}^{m}(\cos \theta),
$$

where $P_{n}^{m}(\cos \theta)$ are the associated Legendre polynomials in Schmidt normalization; coefficients of the spherical harmonic analysis $E_{n}^{m}$, and $e_{n}^{m}$ are determined through the numerical solution of the system of $3 K$ (three magnetic field components, $K$ is the number of ground stations) linear algebraic equations, using the original method of select- ing the optimum spectrum of approximating harmonics [Bazarzhapov et al., 1976, 1979].

Also use the formula of ionospheric plasma drift velocity

$$
\mathbf{V}=\mathbf{E} \times \mathbf{B} / B^{2},
$$

where $\mathbf{E}=-\nabla U, U$ is the electrostatic potential of the ionosphere.

In view of (5), transform the Hall current from (1) into

$$
\mathbf{j}_{\mathrm{H}}=-\left(\Sigma_{\mathrm{H}} B\right) \mathbf{V} \text {. }
$$

From (6) it follows that the ionospheric plasma drift velocity vectors and Hall current vectors are antiparallel, and since, according to (2), equivalent Hall currents flow along isolines of the current function, the ionospheric plasma convection is along these isolines in the opposite direction. Thus, the 2D map of $J(\theta, \lambda)$ isolines is a non-symmetric mirror image of humps and troughs of ionospheric electric potential isolines $U(\theta, \lambda)$. The asymmetry is associated with irregularities of the Hall conductance and geomagnetic field.

The analogy between $J(\theta, \lambda)$ and $U(\theta, \lambda)$ is more obvious in the radial geomagnetic field approximation when the unit vector of the outer normal $\mathbf{n}=\mathbf{r} / r=\mp \mathbf{B} / B$, where “-” corresponds to the Northern Hemisphere; “+”, to the Southern Hemisphere. In this case, given $\mathbf{E}=-\nabla U$, the Hall current from (1) takes the form

$$
\mathbf{j}_{\mathrm{H}}=\mp \Sigma_{\mathrm{H}}(\nabla U \times \mathbf{n}) \text {. }
$$

Equating Formulas (2) and (7), we obtain the desired relationships:

$$
\begin{aligned}
& \nabla J=\mp \Sigma_{\mathrm{H}} \nabla U, \\
& J=\mp \Sigma_{\mathrm{H}} U+\text { const. }
\end{aligned}
$$

From (9) it is evident that for the radial geomagnetic field the current function $J(\theta, \lambda)$ up to a factor $\Sigma_{\mathrm{H}}(\theta, \lambda)$ is a good analog of the electric potential $U(\theta, \lambda)$, and for the uniform Hall conductance the analogy becomes perfect.

From all the above, in this subsection we can conclude that the equivalent current function as an analog of the electric potential of the ionosphere can be used to identify the ionospheric convection reversal boundary.

\subsection{Convection reversal boundary as the maximum rotor of drift velocity}

This third principle of the method stems from the previous two and forms the basis of a new algorithm for diagnostics of auroral oval boundaries and its software implementation.

As described in Subsections 1.1 and 1.2, on the magnetospheric-ionospheric convection reversal boundary the plasma velocity changes both in magnitude and in direction (see Figure 1); hence on the RB boundary the ionospheric plasma drift velocity rotor reaches its maximum value. We derive a formula for the drift velocity rotor in the dipole geomagnetic field in a uniform ionospheric conductance approximation.

Equating Formulas (2) and (6), we get 


$$
\nabla J \times \mathbf{n}=-\left(\Sigma_{\mathrm{H}} B\right) \mathbf{V} .
$$

Apply the rotor operator to both sides of (10). From the "bac-cab" formula and considering that the divergence of the unit normal in the spherical coordinate system is $(\nabla, \mathbf{n})=2 / r$, find the rotor of the left-hand side of (10):

$$
\begin{aligned}
& \nabla \times(\nabla J \times \mathbf{n})=\nabla J(\nabla, \mathbf{n})-\mathbf{n}(\nabla, \nabla J)= \\
& =(2 / r) \nabla J-(\Delta J) \mathbf{n},
\end{aligned}
$$

and from the formula

$$
\nabla \times(S \mathbf{V})=\nabla S \times \mathbf{V}+S(\nabla \times \mathbf{V})
$$

where $S$ and $\mathbf{V}$ are the scalar and vector fields, for the uniform conductance $\Sigma_{\mathrm{H}}$ obtain the rotor of the righthand side of (10):

$$
\nabla \times\left(-\Sigma_{\mathrm{H}} B\right) \mathbf{V}=-\Sigma_{\mathrm{H}} B\left(A_{1}+A_{2}\right),
$$

where $A_{1}=\frac{\nabla B}{B} \times \mathbf{V}$ and $A_{2}=\nabla \times \mathbf{V}$.

Evaluate and compare the characteristic values of $A_{1}$ and $A_{2}$. From the formula of the dipole geomagnetic field

$$
\mathbf{B}=-\left(\mu_{0} M_{\mathrm{E}} / 4 \pi r^{3}\right)\left(2 \cos \theta \mathbf{e}_{r}+\sin \theta \mathbf{e}_{\theta}\right),
$$

where $M_{\mathrm{E}}$ is Earth's magnetic dipole moment, it is easy to estimate $A_{1}$ :

$$
A_{1}=\left|\frac{\nabla B}{B} \times \mathbf{V}\right|_{\text {max }} \approx \frac{\left|\nabla_{\theta} B\right|}{B} V_{\lambda} \approx \frac{3 V_{\lambda}}{r} F(\theta),
$$

where $B=\left(\mu_{0} M_{\mathrm{E}} / 4 \pi r^{3}\right) \sqrt{1+3 \cos ^{2} \theta}$ is the geomagnetic dipole modulus; $\left|\nabla_{\theta} B\right|$ is the value of its latitudinal gradient; $V_{\lambda}$ is the characteristic value of the azimuthal ionospheric drift velocity component, $F(\theta)=\cos \theta \sin \theta /\left(1+3 \cos ^{2} \theta\right)$.

The ionospheric convection reversal boundary RB is almost always located within $10^{\circ} \leq \theta \leq 30^{\circ}$; hence $F(\theta)$ is within $0.05<F(\theta)<0.15$. Given these values of the function, characteristic drift velocity $V_{\lambda} \sim 500 \mathrm{~m} / \mathrm{s}$, and $r=R_{\mathrm{E}}+h$, we obtain from (14) an estimate of the first term in Formula (12):

$$
A_{1} \sim 2 \cdot 10^{-5} \mathrm{~s}^{-1} .
$$

If the azimuthal velocity $\mathbf{V}_{\lambda}$, keeping its value $V_{\lambda} \sim 500 \mathrm{~m} / \mathrm{s}$, reverses on the latitudinal scale $1^{\circ}-5^{\circ} \approx$ $\approx 100-500 \mathrm{~km}$, we get an estimate of the second term in (12):

$$
A_{2}=|\nabla \times \mathbf{V}|_{\max } \approx \partial V_{\lambda} / \partial \theta \sim\left(1 \cdot 10^{-2} \div 2 \cdot 10^{-3}\right) \mathrm{s}^{-1} .
$$

The comparison between estimated $A_{1}$ and $A_{2}$ shows that the second term exceeds the first one by two-three orders of magnitude; we can therefore neglect $A_{1}$ (it is less than $1 \%$ of $A_{2}$ ) and from the condition $A_{2} \gg A_{1}$ reduce Formula (12) to the form

$$
\nabla \times\left(-\Sigma_{\mathrm{H}} B\right) \mathbf{V} \approx-\Sigma_{\mathrm{H}} B(\nabla \times \mathbf{V}) .
$$

Equating now the right-hand sides of (11) and (15), we obtain

$$
(2 / r) \nabla J-(\Delta J) \mathbf{n}=-\Sigma_{\mathrm{H}} B(\nabla \times \mathbf{V}),
$$

which yields the desired equation for the ionospheric plasma drift velocity rotor in the dipole geomagnetic field in the uniform conductance approximation:

$$
\nabla \times \mathbf{V}=\frac{1}{\Sigma_{\mathrm{H}} B}\left[(\Delta J) \mathbf{n}-\frac{2}{r} \nabla J\right] .
$$

The formulas for calculating the gradient $\nabla J$ and surface Laplacian $\Delta J$ can be quite easily derived from Formulas (3) and (4), which determine the equivalent current function $J(\theta, \lambda)$. We do not give here the rather cumbersome formula for calculating the current function gradient modulus $|\nabla J|$, because it is not needed for the subsequent presentation. The formula for calculating $\Delta J$ has the form

$$
\Delta J=\frac{R_{\mathrm{E}}}{\mu_{0} r^{2}} \sum_{n=1}^{N} n(2 n+1)\left(\frac{r}{R_{\mathrm{E}}}\right)^{n} Y_{n}(\theta, \lambda) .
$$

The physical meaning of the surface Laplacian from the equivalent current function $\Delta J(\theta, \lambda)$ is that it represents the spatial FAC density distribution $i_{\|}(\theta, \lambda)$ in the radial geomagnetic field and uniform conductance approximations [Kern, 1966].

Using (2) and (8), Ohm's law (1) can be rewritten as

$$
\mathbf{j}=\frac{\Sigma_{\mathrm{P}}}{\Sigma_{\mathrm{H}}} \nabla J \pm \nabla J \times \mathbf{n},
$$

where, in contrast to (7)-(9), plus is the Northern Hemisphere, minus is the Southern Hemisphere.

By integrating the stationary continuity equation for the current density $\nabla \cdot \mathbf{i}=0$ over the thickness of the conducting layer of the ionosphere, we have

$$
i_{\|}=i_{r}=-\nabla \cdot \mathbf{j},
$$

where the field-aligned current is radial.

Then, by substituting (19) into (20) and considering that $\nabla \cdot \mathbf{j}_{\mathrm{H}}=\nabla \cdot(\nabla J \times \mathbf{n})=0$, we derive a simple formula for the field-aligned (vertical) current density in the given approximation:

$$
i_{\|}=-\frac{\Sigma_{\mathrm{P}}}{\Sigma_{\mathrm{H}}} \Delta J
$$

We use Formula (21) in a more simple form

$$
i_{\|}=-\Delta J
$$

when the conductance ratio $\Sigma_{\mathrm{p}} / \Sigma_{\mathrm{H}}=1$ is not critical for our problem.

Thus, the problem of determining the ionospheric convection reversal boundary $\mathrm{RB}$ reduces to the determination of the closed line at each point of which the drift velocity rotor modulus, calculated from (17), reaches its maximum value.

\section{REALIZATION ALGORITHM AND TESTING OF THE METHOD}

The new automatic method for diagnostics of auroral oval boundaries, based on MIT, first finds the iono- 
spheric convection reversal boundary RB, which is a reference for determining other auroral oval boundaries (R0, R1, and R2).

In this study, to calculate maps of distributions of equivalent and field-aligned currents, we have used data on ground geomagnetic variations, obtained at the worldwide network of stations for August 27, 2001, from the SuperMAG database [Gjerloev, 2012], available on the website of this project [http://supermag.jhuapl.edu]. On the selected date there occurred the well-known isolated substorm between 02:30 and 06:00 UT [Baker et al., 2002; Mishin et al., 2017].

\subsection{The main procedures of the algorithm}

2.1.1. Determining the location of two main extrema on equivalent current function distribution maps

According to the theory and Formulas (17), (21) presented in Sections 1.1 and 1.3, the ionospheric convection reversal boundary as a line of the maximum rotor of the drift velocity vector should be a closed curved line coinciding with the line of maximum density $i_{\|}$of up ward and downward Region 1 FACs. Current function isolines show a characteristic bend, and the gradient modulus $|\nabla J|$ tends to a minimum at each point of this curve. Obviously, as the first reference points of the desired RB boundary we should take points of dawn and dusk current function focuses $J(\theta, \lambda)$ coinciding with Region 1 FAC density distribution focuses $i_{\|}(\theta, \lambda)$. A map of the equivalent current function $J(\theta, \lambda)$ in the Northern Hemisphere for 03:50 UT of August 27, 2001 is given in Figure 2, where points of two main focuses are labeled $A_{1}$ and $B_{1}$. The current function gradient modulus at these reference points is minimum.

2.1.2. Drawing the $R B$ boundary by the minimum modulus of current function gradient

After finding coordinates of the reference points $A_{1}$ and $\mathrm{B}_{1}$, the algorithm with the $J(\theta, \lambda)$ dawn vortex as an

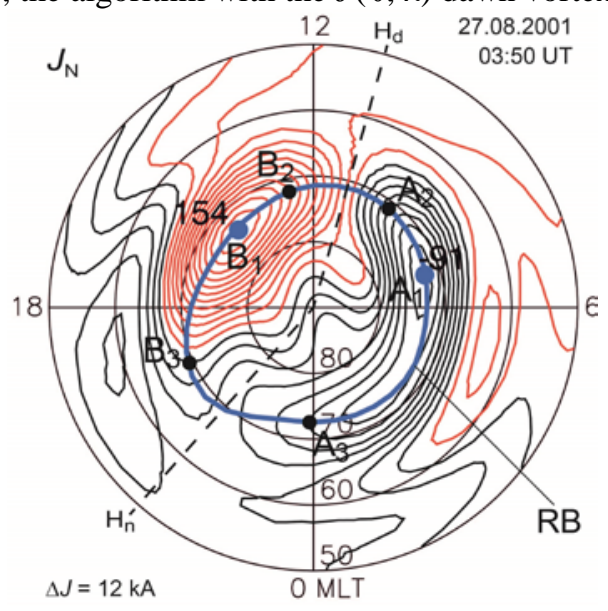

Figure 2. Map of the equivalent current function $J_{\mathrm{N}}$ distribution in the Northern Hemisphere for 03:50 UT of August 27, 2001; $\Delta J$ is the step between isolines. The ionospheric convection reversal boundary $\mathrm{RB}$ is shown by a thick blue line; blue points $A_{1}$ and $B_{1}$ are the locations of the main focuses $J_{N}$; black points $A_{2}, B_{2}$, and $A_{3}, B_{3}$ mark sectors of the daytime $\left(\mathrm{H}_{\mathrm{d}}\right)$ and nighttime $\left(\mathrm{H}_{\mathrm{n}}\right)$ Harang discontinuities (see Section 2.1.2) example works as follows (Figure 2). When moving from the meridian of the $A_{1}$ focus counterclockwise, on each next meridian through $\Delta \lambda=10^{\circ}$ the algorithm finds the latitude of the point such that $|\nabla J| \rightarrow \min$. The movement along the current function gradient modulus minima is accompanied by the control of the condition $\Delta \theta<2^{\circ}$, limiting the maximum jump of the RB latitude between adjacent meridians. A sufficiently smooth segment of the RB curved line is determined up to the $A_{2}$ meridian, where a jump in RB by $\Delta \theta>2^{\circ}$ occurs and the daytime Harang discontinuity sector $\mathrm{H}_{\mathrm{d}}$ begins.

On the $A_{2}$ meridian, the algorithm stops, returns to $A_{1}$, and the entire procedure is performed similarly but clockwise from the $A_{1}$ meridian to the $A_{3}$ meridian, where the RB jump indicates the transition to the sector of the nighttime Harang discontinuity $\mathrm{H}_{\mathrm{n}}$. At $\mathrm{A}_{3}$, the algorithm stops again and proceeds to the analysis of the dusk vortex of the current function with the $B_{1}$ focus. The entire procedure described using the dawn vortex as an example is similarly performed for the dusk vortex of $J(\theta, \lambda)$.

These procedures yield two main RB segments: $A_{3}-$ $A_{1}-A_{2}$ and $B_{2}-B_{1}-B_{3}$. This example corresponds to the substorm growth phase [Mishin et al., 2017] and is sufficiently simple, thus allowing smooth interpolation in the sectors of the daytime $A_{2}-B_{2}$ and nighttime $B_{3}-A_{3}$ Harang discontinuities; and after smoothing with the moving-average method by three points, we can obtain the closed RB boundary in the first approximation (Figure 2).

2.1.3. Searching for additional local extrema and reference points

The algorithm has a very important procedure for diagnostics of meridians of the nighttime $\mathrm{H}_{n}$ and daytime $\mathrm{H}_{\mathrm{d}}$ Harang discontinuities (Figure 2), which is based on the original definition of the term "Harang reversal" coined by Harang [1946] as a boundary between positive $(\Delta H>0)$ and negative $(\Delta H<0)$ bays in the horizontal component of the ground geomagnetic field disturbance in the midnight auroral sector. In the equivalent current function, this definition corresponds to the fact that according to Formula (8) the meridional component of gradient $\nabla_{\theta} J=\Sigma_{\mathrm{H}} E_{\theta}$ changes sign from $\nabla_{\theta} J<0$ to $\nabla_{\theta} J>0$ when passing through the $\mathrm{H}_{\mathrm{n}}$ meridian from the eastward equivalent current to the westward one; when passing clockwise through the $\mathrm{H}_{d}$ meridian the gradient changes sign in the opposite way. The obtained meridians of $\mathrm{H}_{n}$ and $\mathrm{H}_{\mathrm{d}}$ and of $\mathrm{A}_{1}$ and $\mathrm{B}_{1}$ together with the RB boundary in the first approximation (from Section 2.1.2) are then used in a special procedure of the algorithm, which permits the identification of four additional (other than focuses) local extrema on the $J(\theta, \lambda)$ distribution map. During geomagnetic disturbances (substorm, storm), large-scale vortices of the equivalent current function $J(\theta, \lambda)$ may have not one but two or more focuses, which are also considered as reference points for the RB boundary. 


\subsubsection{Forming segments of the RB boundary}

Two major (from 2.1.1) and four additional (from 2.1.3) extrema give six reference points. In the vicinity of each of these points, reference segments for the desired RB boundary are formed based on the rule $|\nabla J| \rightarrow \min$ and condition $\Delta \theta<2^{\circ}$, described in Subsection 2.1.2. After determining six reference segments, we perform interpolation between them, in particular in the sectors of the nighttime and daytime Harang discontinuities, as well as three-point smoothing of the boundary.

This yields the ionospheric convection reversal boundary constructed entirely from the scalar field of the equivalent current function.

2.1.5. Constructing the $R B$ boundary by the maximum density of Region 1 FACs

According to (17) and (21), a strict maximum of the rotor of the drift velocity vector is achieved at the point where two conditions are simultaneously satisfied: (I) $|\nabla J| \rightarrow \min$ and (II) $|\nabla J|=\left|i_{\|}\right| \rightarrow \max$. For convenience, designate the ionospheric convection reversal boundary, obtained using the algorithm based on condition (I) and described in 2.1.1-2.1.4, as RB-I. The second algorithm is based on condition (II) and uses RB-I obtained by the first algorithm as a reference. This boundary is plotted on the FAC density distribution map. As follows from the theory, RB-I is on the map of $i_{\|}(\theta, \lambda)$ approximately along the line of maximum density of Region 1 FACs. Then, on each meridian, we analyze latitudinal profiles $i_{\|}(\theta)$, and in the Region 1 FACs near RB-I determine latitudes of points such that $\left|i_{\|}\right| \rightarrow \max$. As a result, we find two longitudinally extended segments of the boundary located within areas of downward (dawn) and upward (dusk) Region 1 FACs. As in the first algorithm, in the sectors of the nighttime and daytime Harang discontinuities we perform interpolation between the obtained segments, and then threepoint smoothing of the closed curve. As a result, we have the RB-II boundary passing along the line of maximum density of Region 1 FACs (Figure 3).
By combining conditions (I) and (II) and results of the two algorithms, we calculate the final RB boundary as the average of RB-I and RB-II.

2.1.6. Polar cap boundary, auroral oval equatorial boundary, and line of maximum density of auroral electrojets

When moving from the obtained RB boundary (or from adjacent RB-II) southward, the algorithm analyzes the density profile $i_{\|}(\theta)$ on each meridian and finds the latitude at which $i_{\|}$changes sign, thus indicating the R1 boundary between FACs of Regions 1 and 2. Since the R1 boundary is identified with the line of maximum density of auroral electrojets, to determine it more precisely we additionally use the map of distribution of the current function gradient modulus $|\nabla J(\theta, \lambda)|$, calculated from Formulas (3) and (4). The R1 boundary is corrected on each meridian, taking into account locations of $|\nabla J|$ maxima. This procedure yields a smoothed R1 boundary between FACs of Regions 1 and 2 - the line of maximum density of westward and eastward auroral electrojets (Figure 3).

When moving through FAC Region 2 from the R1 boundary further southward, from the $i_{\|}(\theta)$ profile we determine first the line of maximum density of Region 2 FACs, then the boundary at which this density reaches zero, i.e. the auroral oval equatorial boundary R2 (see Figure 3).

Similarly we find the polar cap boundary R0. When analyzing the latitudinal profiles $i_{\|}(\theta)$ in FAC Region 1 northward of the RB boundary (or RB-II), on each meridian we find points, where the Region 1 FAC density goes to zero. In this case, as an additional reference point, we use the estimate of the polar cap boundary location from the formula $\mathrm{R} 0=2 \mathrm{RB}-\mathrm{R} 1$, which follows from the fact that the maximum density in $i_{\|}(\theta)$ passes through the center of FAC Region 1 (Figure 3).

Thus, the automatic algorithm for diagnostics of auroral oval boundaries, described in Section 2.1, gives its four main boundaries at the output: RB, R1, R2, and R0.

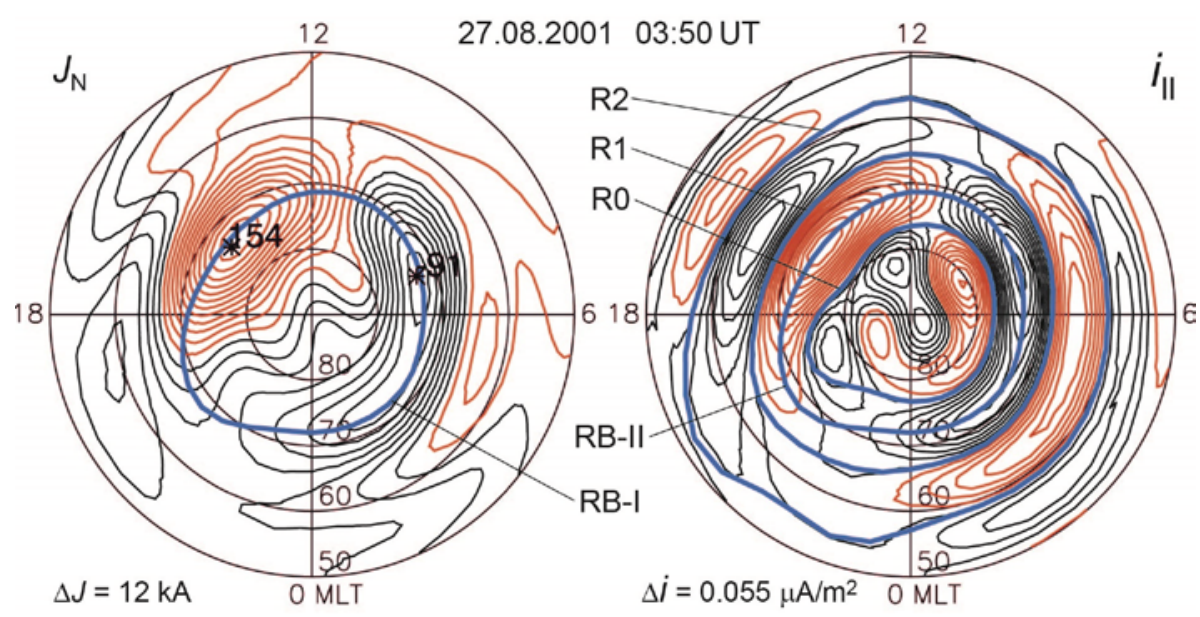

Figure 3. Maps of distributions of the equivalent current function $J_{\mathrm{N}}$ (left) and density of FAC with uniform conductance $i_{\|}$ (right) in the Northern Hemisphere for 03:50 UT of August 27, 2001; black isolines on the map of $i_{\|}$correspond to downward FACs; red isolines, to upward ones; $\Delta J$ and $\Delta i$ are steps between isolines; RB-I and RB-II are the convection reversal boundaries derived from maps of $J_{\mathrm{N}}$ and $i_{\|}$under conditions (I) and (II) respectively (see 2.1.5); R0, R1, and R2 are the polar cap boundary, line of maximum density of auroral electrojets, and auroral oval equatorial boundary, determined from the map of $i_{\|}$ 


\subsection{Comparing the manual and automatic methods}

As already noted in Introduction, before the development of the automatic algorithm, all the procedures described in Section 2.1 were made with the visual-manual method: analyzing maps of distributions of equivalent and field-aligned currents with uniform conductivity on the screen, an operator in a special program draws the R0, R1, and R2 boundaries with a mouse along profiles of zero isolines bounding FACs of Regions 1 and 2 on the $i_{\|}(\theta, \lambda)$

density map, by interpolating the boundaries "by eye” in the Harang sectors. The operator does not draw the RB boundary, but estimates it from $\mathrm{RB}=\mathrm{R} 0+(\mathrm{R} 1-\mathrm{R} 0) / 2$. It takes $10 \mathrm{~min}$ to process one map of $i_{\|}(\theta, \lambda)$. A limitation of the manual method is also the human factor: the same operator at different times may draw different boundaries on the same map, as well as boundaries drawn by several operators on a given map may differ.

The automatic method for diagnostics of auroral oval boundaries has no such limitations of the visual-manual method and cuts time of construction of the boundaries by two or three orders of magnitude. To quantitatively compare the two methods, using MIT we have calculated maps of $J(\theta, \lambda)$ and $i_{\|}(\theta, \lambda)$ for 133 instants of the interval
02:30-06:00 UT of the August 27, 2001 isolated substorm. For each instant, we identified the R0, RB, R1, and R2 boundaries with both manual and automatic methods.

The visual comparison between the boundaries for all the instants leads to the conclusion that the boundaries obtained by the two methods generally coincide. Figure 4 gives an example illustrating good qualitative agreement of all auroral oval boundaries obtained by the manual (top row) and automatic (bottom row) methods.

The quantitative comparison between the manual and automatic methods for determining the R0, RB, R1, and R2 boundaries was made using the quantile method including all the 133 instants and 36 meridians in one statistical sample: $133 \times 36=4788$ colatitude values for each boundary. The results of the comparison are given in Figure 5. It is apparent that for the R0, RB, and R1 boundaries the two methods are consistent with the high correlation coefficient $r=0.74-0.83$ and with small RMS $=2.0^{\circ}-2.5^{\circ}$, approximately equal to two steps $\left(2 \times 1^{\circ}\right)$ of the computation grid in latitude. By the R2 boundary the correlation coefficient corresponds to the average level for the same value of the root-meansquare deviation.
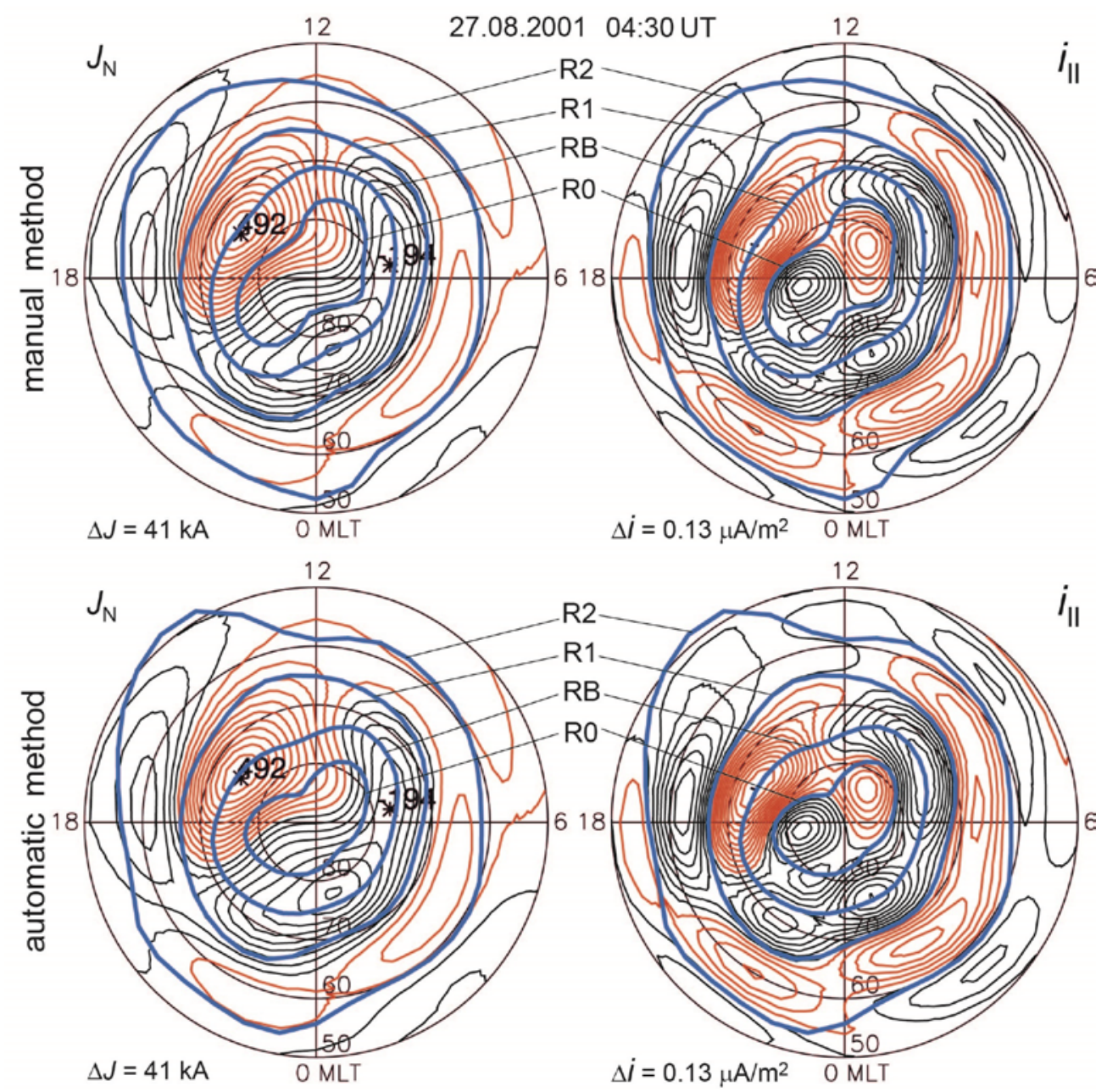

Figure 4. The same data format as in Figure 3 for 04:30 UT of August 27, 2001. The R0, RB, R1, and R2 boundaries in the top row are found by the visual-manual method; in the bottom row, by the automatic method 

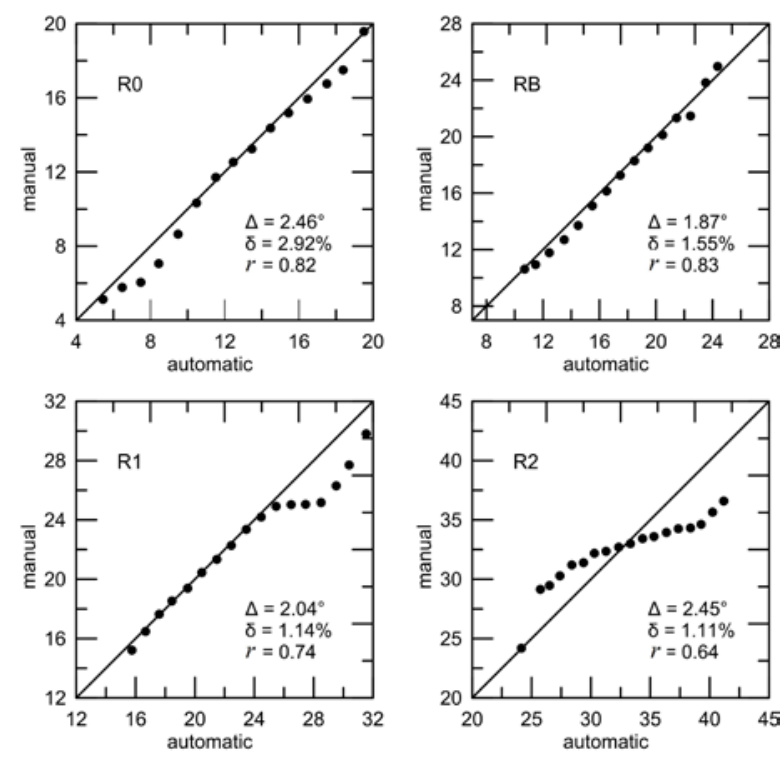

Figure 5. Statistical comparison between the manual and automatic methods for determining R0, RB, R1, and R2 boundaries; $\mathrm{X}$ - and Y-axes are colatitudes of respective boundaries. Estimates of the absolute $\Delta$ and relative $\delta$ errors and the correlation coefficient $r$ are shown on quantile plots

At the end of Section 2, we present a qualitative comparison of the ionospheric convection reversal boundary obtained by the automatic method based onoutput parameters of MIT with the distribution of the electric potential obtained from SuperDARN data. The convection reversal boundary RB obtained for 04:30 UT on August 27, 2001 (see Figure 4) is plotted on the map of the RG96 statistical model for the selected time (Figure 6), taken from the SuperDARN VT site [http://vt.superdarn.org/tiki-index.php]. Figure 6 shows that the RB boundary passes almost through focuses of electric potentials of the dawn and dusk vortices, located near the 06-18 MLT meridian.

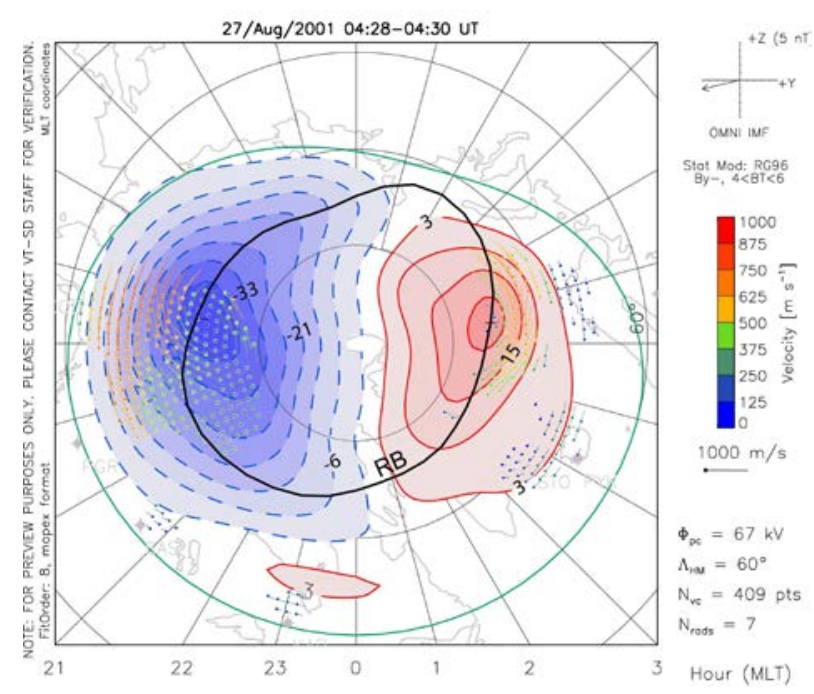

Figure 6. Ionospheric convection reversal boundary (RB, thick black line), determined with the new automatic method for 04:30 UT of August 27, 2001 and plotted on the electric potential distribution map of the statistical model RG96 (taken from the VT SuperDARN site [http://vt.superdarn.org/tikiindex.php])
The location of these focuses is reliably confirmed by direct measurements of drift velocities with radars located in areas surrounding the focuses. Figure 6 also indicates that the RB boundary covers almost entire antisunward convection, passing approximately through the convection reversal line visible on the electric potential map of the RG96 model.

\section{DISCUSSION}

Let us consider here three fundamental questions directly related to our method for diagnostics of auroral oval boundaries from MIT output data.

\subsection{Radial geomagnetic field approximation}

From the geomagnetic dipole formulas $B_{\theta} / B_{r}=0.5 \tan \theta$ and $B_{\theta} / B_{r}=1 / \tan I$ it follows that the magnetic inclination of the dipole field line is $I=\arctan (2 / \tan \theta)$. Using this formula, we obtain an estimate of the relative error $\delta(\%)=100 \cdot\left|I-90^{\circ}\right| / 90^{\circ}$ of the radial approach: $5<\delta<18 \%$ in the auroral region $10^{\circ}<\theta<30^{\circ}$.

The question about radiality is directly related to the magnetic effect of field-aligned currents on Earth's surface. Given $I=90^{\circ}$, FACs are strictly vertical, are closed by horizontal Pedersen currents, and with the uniform ionospheric conductance the total ground magnetic effect of both the currents is zero [Fukushima, 1976]. In such a case, ground geomagnetic variations are entirely caused by divergence-free equivalent Hall currents. Sun et al. [1985] have calculated the ground magnetic effect of the 3D current system in Earth's dipole field and have found that the FAC contribution in the highlatitude region of $10^{\circ}<\theta<30^{\circ}$ is $5-20 \%$, which agrees with our simplest estimate.

\subsection{Correspondence between equivalent and real Hall currents}

This question was first considered only theoretically [Kern, 1966; Vasyliūnas, 1970; Fukushima, 1976], but later Sugiura [1984] from simultaneous measurements of electric and magnetic fields on board the satellite DE-2 concluded that the divergence of ionospheric Hall currents is nearly zero, and field-aligned currents are largely closed by meridional Pedersen currents. Laundal et al. [2015] in an in-depth study have found that the equivalent and real Hall currents can perfectly match only in the case of uniform ionospheric conductance or when conductance gradients are perpendicular to ionospheric convection lines. Let us discuss this.

In the radial magnetic field approximation, from (1), (5) it is easy to derive for the Northern Hemisphere expressions $\nabla \cdot \mathbf{j}_{\mathrm{H}}=-B\left(\nabla \Sigma_{\mathrm{H}} \cdot \mathbf{V}\right)$ and $\nabla \times \mathbf{j}_{\mathrm{P}}=-B\left(\nabla \Sigma_{\mathrm{P}} \cdot \mathbf{V}\right) \mathbf{n}$, determining the divergence Hall component and the Pedersen component of real ionospheric current rotor (1). From these expressions it follows that $\nabla \cdot \mathbf{j}_{\mathrm{H}}=0$ and $\nabla \times \mathbf{j}_{\mathrm{P}}=0$ in three cases: (i) $\Sigma_{\mathrm{P}}=\Sigma_{\mathrm{H}} \rightarrow 0$ is a very low conductance (on the background level); (ii) 
$\nabla \Sigma_{\mathrm{P}}=\nabla \Sigma_{\mathrm{H}}=0$ is a uniform ionospheric conductances; (iii) $\nabla \Sigma_{\mathrm{P}} \cdot \mathbf{V}=\nabla \Sigma_{\mathrm{H}} \cdot \mathbf{V}=0$, i.e. conductance gradients are perpendicular to ionospheric convection lines. If any of these conditions holds, the real Pedersen current is entirely curl-free, i.e. $\mathbf{j}_{\mathrm{p}}=\mathbf{j}_{\mathrm{cf}}$, and the real Hall current becomes strictly divergence-free and equal to the equivalent Hall current: $\mathbf{j}_{\mathrm{H}}=\mathbf{j}_{\mathrm{df}}=\mathbf{j}_{\mathrm{eq}}=\nabla J \times \mathbf{n}$.

Conditions (iii) holds quite well in regions of the reverse ionospheric convection corresponding to auroral electrojets, which are the main source of ground geomagnetic variations.

In these two extended local time sectors, gradients of the ionospheric conductances generally have the meridional component; and the convection velocity, an azimuthal component. In the sectors of daytime and nighttime Harang discontinuities, condition (iii) is violated. In the polar cap, the conditions are similar to (ii), except for the region near the terminator.

\subsection{Field-aligned currents and ionospheric convection reversal boundary}

The term "cabling" for the currents flowing along magnetic field lines was coined for magnetospheric physics by Hannes Alfvén [Alfvén, 1981]. Just as two high-power transmitting cables connect a man-made generator with a power consumer, a pair of plasma "cables" - Region 1 FACs - connects the natural magnetospheric generator with a load (ionosphere). The cables of Region 1 FACs represent two longitudinally extended thin sheets connected in the dawn and dusk to the ionosphere on the ionospheric convection reversal boundary (see Figure 1). Of fundamental importance is the fact that the central place of cable connection to the ionosphere (the maximum density of Region 1 FACs $\mathrm{RB}$ boundary) does not depend on the manner in which it is found (from satellite or radar data, or by the new extended MIT). A confirmation of this fundamental property of the RB boundary is Figure 6, where two independent ground-based methods (SuperDARN and MIT) give identical convection reversal boundaries.

In MIT, the spatial structure of equivalent and fieldaligned currents is determined by the spectrum $\{n, m\}$ of spherical harmonic functions in Formulas (3), (4), and (18). If the $\{n, m\}$ spectrum is represented as an analog of a "ruler", which is used in MIT to measure the $\mathrm{RB}$ location relative to the pole, due to the above fundamental property the RB latitude should be largely independent of the length of the spectrum (ruler scale). We have done a simple test of this fundamental principle. We calculated maps of distributions of $J(\theta, \lambda)$ and $i_{\|}(\theta, \lambda)$ for 03:50 UT of August 27, 2001 with $\{n, m\}=\{1,2,3, \ldots, N ; 0,1,2, \ldots, n\}$, where the maximum value $N$ (ruler scale) was variable: $N=16$, $17,18, \ldots, 50$. On the maps of $J(\theta, \lambda)$, we determined coordinates of focuses of dawn and dusk convection vortices and investigated the $N$ dependence of the colatitude of these focuses. We have established that throughout the given $N$ interval the colatitude of the dawn focus varies within $18.3^{\circ} \pm 1.1^{\circ}$; and that of the dusk one, within $17.5^{\circ} \pm 0.9^{\circ}$, where the first number is the average, and the second is the standard deviation comparable to $1^{\circ}$ step of the computation grid in latitude accepted in all MIT programs. The above test leads to an important methodical conclusion: the RB boundary location, diagnosed with MIT, is essentially independent of the length of the spectrum of spherical harmonics. Accordingly, the result (Figure 6) of the comparison between the independent methods is even more convincing.

\subsection{Ionospheric conductance, electric poten- tial, and field-aligned currents}

In the 3D analysis of MIT [Matveev, Shpynev, 1975; Bazarzhapov et al., 1979; Kamide, Matsushita, 1979; Kamide, Baumjohann, 1993], the electric potential and field-aligned currents in the polar ionosphere are calculated from

$$
\begin{aligned}
& \operatorname{rot}_{r}(\hat{\Sigma} \cdot \nabla U)=-\Delta J, \\
& \operatorname{div}_{\perp}(\hat{\Sigma} \cdot \nabla U)=i_{\|} \sin I,
\end{aligned}
$$

where $\hat{\Sigma}$ is the tensor of non-uniform integral ionospheric conductances; $U$ is the electric potential; $\Delta J$ is surface Laplacian from the equivalent current function; $\operatorname{rot}_{r}$ is the radial component of rotor; $\operatorname{div}_{\perp}$ is the $2 \mathrm{D}$ divergence operator; $i_{\|}$is the FAC density; $I$ is the magnetic inclination. First, Equation (23) is solved numerically for the electric potential $U$ for the given conductance model $\hat{\Sigma}$ and with the right-hand side calculated from Formula (18). Then, using the obtained solution of $U$ and the model $\hat{\Sigma}$, from Formula (24) we calculate $i_{\|}$.

Already in the first papers on the application of the 3D analysis in MIT [Mishin et al., 1981; Kamide, Richmond, 1982; Reiff, 1984], the correctness of the solution of (23) for $U$ has been found to depend strongly on the selected model $\hat{\Sigma}$, and specifically on the spatial adjustment of irregularities of the tensor $\hat{\Sigma}$ with the inhomogeneous right-hand side of (23). The correct solution should have the form of the large-scale twovortex system of $U$ isolines, which is generally similar to the large-scale two-vortex equivalent current system $J$, as discussed in 1.2 and 3.2. The match between the lefthand and right-hand sides of (23) is provided by auroral oval boundaries, which are studied in this work and included in the dynamic conductance model developed at ISTP SB RAS [Mishin et al., 1986; Shirapov et al., 2000].

In the same papers [Mishin et al., 1981; Kamide, Richmond, 1982], and then in the long-term practice of solving Equations (23) and (24) it have been established that unlike the electric potential the large-scale structure of main FAC Iijima-Potemra Regions 1 and 2 and, consequently, their related auroral oval boundaries depend weakly on the conductance model. The physical meaning of this fact is clear from the equation

$$
i_{\|}=i_{r}=-\Sigma_{\mathrm{P}} \nabla \cdot \mathbf{E}-\nabla \Sigma_{\mathrm{P}} \cdot \mathbf{E}-\nabla \Sigma_{\mathrm{H}} \cdot(\mathbf{E} \times \mathbf{n}),
$$

derived from Formulas (1) and (24) for the Northern Hemisphere in the radial approximation.

Using Formula (25), Boström [1974] classified FAC sources into primary and secondary: the primary (main) magnetospheric source of large-scale FACs is 
determined by the first term of (25); secondary ionospheric sources of mesoscale FACs associated with electric fields of polarization on conductance gradient, by the second and third terms of (25). Since $\nabla \cdot \mathbf{E}=\rho /\left(\varepsilon \varepsilon_{0}\right)$ and $\mathbf{E}=-\nabla U$, then $\nabla \cdot \mathbf{E}=-\Delta U$ and (25) yield FAC of the magnetospheric source $i_{r, m}=\Sigma_{\mathrm{p}} \Delta U$, where $\Delta U=-\rho /\left(\varepsilon \varepsilon_{0}\right), U$ is the electrostatic potential transmitted by Region 1 FACs from the magnetospheric generator to the ionosphere (see Figure 1).

Large-scale FACs of Regions 1 and 2 of magnetospheric origin form the basis for our method of diagnostics of auroral oval boundaries (2.1.6). In view of the above, the 2D maps of FACs calculated in the uniform ionospheric conductance approximation provide sufficient accuracy in determining the auroral oval boundaries. Figure 7 illustrates a very high degree of similarity of large-scale FACs calculated in two ways: with uniform (left) and non-uniform (right) ionospheric conductances. A close similarity between FAC maps can be seen both in moderately disturbed conditions during the growth phase (top row) and during the magnetic sub- storm expansion phase (bottom row). The auroral oval boundaries R0, R1, and R2 of the left panel (uniform conductances) are superimposed on the FAC map of the right panel (non-uniform conductances). It is apparent that up to $2^{\circ}$ (what corresponds to two steps of the computation grid in latitude), these R0, R1, and R2 boundaries go along the boundaries (zero isolines) of largescale FACs of Regions 1 and 2, calculated with the nonuniform conductance model [Shirapov et al., 2000].

\section{CONCLUSION}

Let us present the main results obtained in this study.

1. The ionospheric convection reversal boundary has been shown to be the fundamental parameter of the magnetosphere-ionosphere coupling. We have theoretically analyzed the relationship between the electrostatic potential of the ionosphere and the equivalent current function in the approximation of the dipole geomagnetic field and uniform ionospheric conductance. We have derived an equation for the ionospheric plasma drift velocity rotor, expressed through the current function. The rotor maximum determines the ionospheric convection reversal boundary.
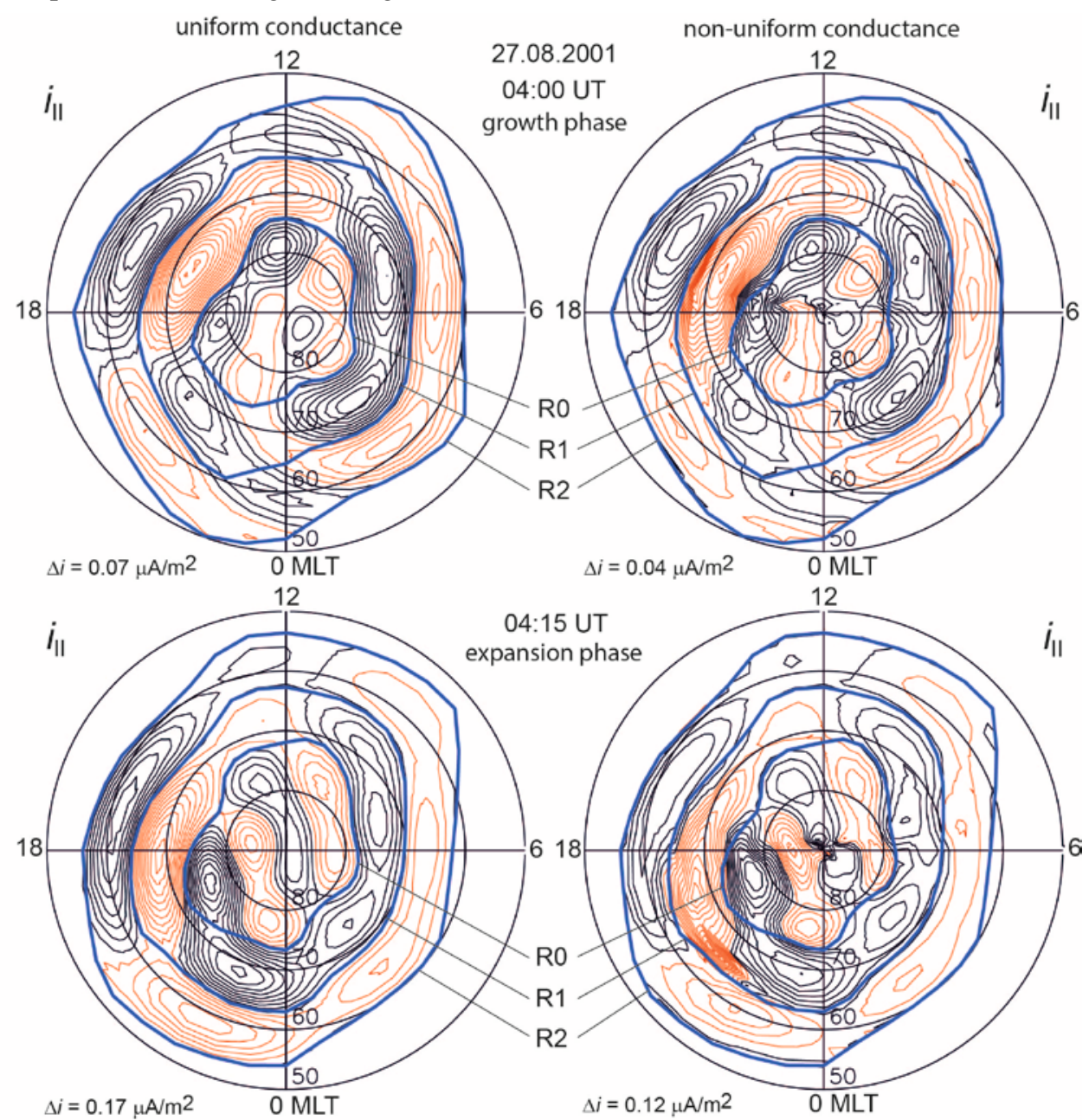

Figure 7. Distribution maps of FAC density $i_{\|}$for the growth phase (04:00 UT) and expansion phase (04:15 UT) of the August 27, 2001 magnetic substorm, calculated with uniform (left) and non-uniform (right) ionospheric conductances. The auroral oval boundaries R0, R1, and R2 (blue bold lines) determined on the FAC maps for the uniform conductance are plotted on the respective FAC maps for non-uniform conductance. See text for details 
2. We have developed a new ground-based method for diagnostics of auroral oval boundaries from output data obtained by the magnetogram inversion technique. Using distribution maps of current function and field-aligned currents at the uniform ionospheric conductance, we determine ionospheric convection reversal boundary, polar cap boundary, auroral oval equatorial boundary, and line of maximum density of auroral electrojets.

3. The new method is implemented as an algorithm and software for automatic determination of these auroral oval boundaries. The comparison with the visual-manual method has shown that the new automatic method provides sufficient accuracy in determining all boundaries no worse than a human operator, reducing the time required to process the necessary amount of data by two or three orders of magnitude.

The work was performed with budgetary funding of Basic Research program II.16 and with partial support from RFBR grant No. 18-05-00437. The authors thank V.M. Mishin, V.V. Mishin, and A.V. Tashchilin for their interest in this work and useful discussions.

For the ground magnetometer data we gratefully acknowledge the following: Intermagnet; USGS, Jeffrey J. Love; CARISMA, PI Ian Mann; CANMOS; The S-RAMP Database, PI K. Yumoto and Dr. K. Shiokawa; The SPIDR database; AARI, PI Oleg Troshichev; The MACCS program, PI M. Engebretson, Geomagnetism Unit of the Geological Survey of Canada; GIMA; MEASURE, UCLA IGPP and Florida Institute of Technology; SAMBA, PI Eftyhia Zesta; 210 Chain, PI K. Yumoto; SAMNET, PI Farideh Honary; The institutes who maintain the IMAGE magnetometer array, PI Eija Tanskanen; PENGUIN; AUTUMN, PI Martin Connors; DTU Space, PI Dr. Rico Behlke; South Pole and McMurdo Magnetometer, PI's Louis J. Lanzarotti and Alan T. Weatherwax; ICESTAR; RAPIDMAG; PENGUIn; British Artarctic Survey; McMac, PI Dr. Peter Chi; BGS, PI Dr. Susan Macmillan; Pushkov Institute of Terrestrial Magnetism, Ionosphere and Radio Wave Propagation (IZMIRAN); GFZ, PI Dr. Juergen Matzka; MFGI, PI B. Heilig; IGFPAS, PI J. Reda; University of L'Aquila, PI M. Vellante; BCMT, V. Lesur and A. Chambodut; Data obtained in cooperation with Geoscience Australia, PI Marina Costelloe; SuperMAG, PI Jesper W. Gjerloev. Data used in this study are available from the SuperMAG web site [http://supermag.jhuapl.edu].

\section{REFERENCES}

Akasofu S.I. Polar and Magnetospheric Substorms. Dordrecht, Holland, Springer Netherlands, 1968, 280 p. DOI: 10.1007/978-94-010-3461-6.

Akasofu S.I. Physics of Magnetospheric Substorms. Dordrecht, Holland, Springer Netherlands, 1977, 617 p. DOI: 10.1007/978-94-010-1164-8_1.

Alfvén H. Cosmic plasma. Dordrecht, Holland, Springer Netherlands, 1981, 168 p. DOI: 10.1007/978-94-009-8374-8.

Axford W.I., Hines C.O. A Unifying theory of high-latitude geophysical phenomena and geomagnetic storms. Can. J. Phys. 1961, vol. 39, no. 10, pp. 1433-1464. DOI: 10.1139/p61-172.

Baker D.N., Peterson W.K., Eriksson S., Li X., Blake J.B., Burch J.L., Daly P.W., Dunlop M.W., Korth A., Donovan E., Friedel R., Fritz T.A., Frey H.U., Mende S.B., Roeder J., Singer H.J. Timing of magnetic reconnection initiation during a global magnetospheric substorm onset. Geophys. Res. Lett. 2002, vol. 29, no. 24, pp. 2190. DOI: 10.1029/2002GL015539.

Bazarzhapov A.D., Mishin V.M., Shpynev G.B. A mathe- matical analysis of geomagnetic variation fields. Gerlands Beitr. Geophysik. 1976, vol. 85, no. 1, pp. 76-82.

Bazarzhapov A.D., Matveev M.I., Mishin V.M. Geomagnitnye variatsii $i$ buri [Geomagnetic Variations and Storms]. Novosibirsk, Nauka Publ. 1979, 248 p. (In Russian).

Boakes P.D., Milan S.E., Abel G.A., Freeman M.P., Chisham G., Hubert B., Sotirelis T. On the use of IMAGE FUV for estimating the latitude of the open/closed magnetic field line boundary in the ionosphere. Ann. Geophys. 2008, vol. 26, no. 9, pp. 2759-2769. DOI: 10.5194/angeo-26-2759-2008.

Boström R. Ionosphere-magnetosphere coupling. Magnetospheric Physics. Ed. by B.M. McCormac. D. Reidel Publishing Company, Dordrecht-Holland, 1974, pp. 45-59.

Bristow W.A., Spaleta J. An investigation of the characteristics of the convection reversal boundary under southward interplanetary magnetic field. J. Geophys. Res.: Space Phys. 2013, vol. 118, no. 10, pp. 6338-6351. DOI: 10.1002/ jgra.50526.

Chapman S., Bartels J. Geomagnetism. Vol. 2. Great Britain, Oxford University Press, 1940, 520 p.

Chen Y.J., Heelis R.A., Cumnock J.A. Response of the ionospheric convection reversal boundary at high latitudes to changes in the interplanetary magnetic field. J. Geophys. Res.: Space Phys. 2015, vol. 120, no. 6, pp. 5022-5034. DOI: 10.1002/ 2015ja021024.

Drake K.A., Heelis R.A., Hairston M.R., Anderson P.C. Electrostatic potential drop across the ionospheric signature of the low-latitude boundary layer. J. Geophys. Res. 2009, vol. 114, no. A4. DOI: $10.1029 / 2008 j a 013608$.

Dungey J.W. Interplanetary magnetic field and the auroral zones. Phys. Rev. Lett. 1961, vol. 6, no. 2, pp. 47-48. DOI: 10.1103/PhysRevLett.6.47.

Feldstein Y.I. Polar auroras, polar substorms, and their relationships with the dynamics of the magnetosphere. Rev. Geophys. 1969, vol. 7, no. 1-2, pp. 179-218. DOI: 10.1029/RG 007i001p00179.

Feldstein Y.I. The discovery and the first studies of the auroral oval: A review. Geomagnetism and Aeronomy. 2016, vol. 56, no. 2, pp. 129-142. DOI: 10.1134/s0016793216020043.

Feldstein Y.I., Starkov G.V. Dynamics of auroral belt and polar geomagnetic disturbances. Planet. Space Sci. 1967, vol. 15, no. 2, pp. 209-229. DOI: 10.1016/0032-0633(67)90190-0.

Fukushima N. Generalized theorem for no ground magnetic effect of vertical currents connected with Pedersen currents in the uniform-conductivity ionosphere. Report of Ionosphere and Space Research in Japan. 1976, vol. 30, no. 1-2, pp. 35-40.

Gjerloev J.W. The SuperMAG data processing technique. $J$. Geophys. Res. 2012, vol. 117, no. A9, pp. A09213. DOI: 10.1029/ 2012ja017683.

Gussenhoven M.S., Hardy D.A., Heinemann N. Systematics of the equatorward diffuse auroral boundary. J. Geophys. Res. 1983, vol. 88, no. A7, pp. 5692-5708. DOI: 10.1029/JA088iA07p05692.

Haaland S., Lybekk B., Maes L., Laundal K., Pedersen A., Tenfjord P., Ohma A., Østgaard N., Reistad J., Snekvik K. Northsouth asymmetries in cold plasma density in the magnetotail lobes: Cluster observations. J. Geophys. Res.: Space Phys. 2017, vol. 122, no. 1, pp. 136-149. DOI: 10.1002/2016ja023404.

Haines G.V., Torta J.M. Determination of equivalent current sources from spherical cap harmonic models of geomagnetic field variations. Geophys. J. Int. 1994, vol. 118, no. 3, pp. 499-514. DOI: 10.1111/j.1365-246X.1994.tb03981.x.

Harang L. The mean field of disturbance of polar geomagnetic storms. Terr. Magn. Atmos. Electr. 1946, vol. 51, no. 3, pp. 353-380. DOI: 10.1029/TE051i003p00353.

Heikkila W.J. Earth's Magnetosphere: Formed by the LowLatitude Boundary Layer. Amsterdam, Elsevier Science, 2011, 536 p. DOI: 10.1016/B978-0-444-52864-3.10012-7.

Heppner J.P. Electric field variations during substorms: OGO6 measurements. Planet. Space Sci. 1972, vol. 20, no. 9, pp. 
1475-1498. DOI: 10.1016/0032-0633(72)90052-9.

Hubert B., Aikio A.T., Amm O., Pitkänen T., Kauristie K., Milan S.E., Cowley S.W.H., Gérard J.C. Comparison of the openclosed field line boundary location inferred using IMAGE-FUV SI12 images and EISCAT radar observations. Ann. Geophys. 2010, vol. 28, no. 4, pp. 883-892. DOI: 10.5194/angeo-28-8832010.

Iijima T., Potemra T.A. Large-scale characteristics of fieldaligned currents associated with substorms. J. Geophys. Res. 1978, vol. 83, no. A2, pp. 599-615. DOI: 10.1029/JA083i A02p00599.

Kamide Y., Matsushita S. Simulation studies of ionospheric electric fields and currents in relation to field-aligned currents. 1. Quiet periods. J. Geophys. Res. 1979, vol. 84, no. A8, pp. 40834098. DOI: 10.1029/JA084iA08p04083.

Kamide Y., Richmond A.D. Ionospheric conductivity dependence of electric fields and currents estimated from ground magnetic observations. J. Geophys. Res. 1982, vol. 87, no. A10, pp. 8331-8337. DOI: 10.1029/JA087iA10p08331.

Kamide Y., Baumjohann W. Magnetosphere-ionosphere coupling. Berlin, Springer Berlin Heidelberg, 1993, 178 p. DOI: 10.1007/978-3-642-50062-6.

Kern J.W. Analysis of Polar Magnetic Storms. J. Geomag. Geoelectr. 1966, vol. 18, no. 2, pp. 125-131. DOI: 10.5636/jgg. 18.125.

Koustov A.V., Fiori R.A.D. Seasonal and solar cycle variations in the ionospheric convection reversal boundary location inferred from monthly SuperDARN data sets. Ann. Geophys. 2016, vol. 34, no. 2, pp. 227-239. DOI: 10.5194/angeo34-227-2016.

Laundal K.M., Haaland S.E., Lehtinen N., Gjerloev J.W., Østgaard N., Tenfjord P., Reistad J.P., Snekvik K., Milan S.E., Ohtani S., Anderson B.J. Birkeland current effects on highlatitude ground magnetic field perturbations. Geophys. Res. Lett. 2015, vol. 42, no. 18, pp. 7248-7254. DOI: 10.1002/ 2015 gl065776.

Lazutin L.L. Auroral oval as a beautiful but outdated paradigm. Solnechno-zemnaya fizika [Solar-Terrestrial Phys.]. 2015, vol. 1, no. 1, pp. 23-35. DOI: 10.12737/5673. (In Russian).

Longden N., Chisham G., Freeman M.P., Abel G.A., Sotirelis T. Estimating the location of the open-closed magnetic field line boundary from auroral images. Ann. Geophys. 2010, vol. 28, no. 9, pp. 1659-1678. DOI: 10.5194/ angeo-28-1659-2010.

Makita K., Meng C.I., Akasofu S.I. The shift of the auroral electron precipitation boundaries in the dawn-dusk sector in association with geomagnetic activity and interplanetary magnetic field. J. Geophys. Res. 1983, vol. 88, no. A10, pp. 7967-7981. DOI: 10.1029/JA088iA10p07967.

Makita K., Meng C.I., Akasofu S.I. Temporal and spatial variations of the polar cap dimension inferred from the precipitation boundaries. J. Geophys. Res. 1985, vol. 90, no. A3, pp. 2744-2752. DOI: 10.1029/JA090iA03p02744.

Matveev M.I., Shpynev G.B. Determination of electric fields and field-aligned currents in the magnetosphere on data of geomagnetic variations (high-latitude region). Issledovaniya po geomagnetizmu, aeronomii $i$ fizike Solntsa [Research on Geomagnetism, Aeronomy and Solar Physics]. 1975, no. 36, pp. 34-39. (In Russian).

Milan S.E., Provan G., Hubert B. Magnetic flux transport in the Dungey cycle: A survey of dayside and nightside reconnection rates. J. Geophys. Res. 2007, vol. 112, no. A1, pp. A01209. DOI: 10.1029/2006ja011642.

Milan S.E., Evans T.A., Hubert B. Average auroral configuration parameterized by geomagnetic activity and solar wind conditions. Ann. Geophys. 2010, vol. 28, no. 4, pp. 10031012. DOI: 10.5194/angeo-28-1003-2010.

Mishin V.M. The magnetogram inversion technique and some applications. Space Sci Rev. 1990, vol. 53, no. 1-2, pp. 83163. DOI: 10.1007/bf00217429.
Mishin V.M., Shpynev G.B., Bazarshapov A.D., Shirapov D.S. Electric field and currents in the nonuniformly-conductivo high-latitude ionosphere. Issledovaniya po geomagnetizı aeronomii $i$ fizike Solntsa [Research on Geomagnetis..., Aeronomy and Solar Physics]. 1981, no. 53, pp. 116-133. (In Russian).

Mishin V.M., Lunyushkin S.B., Shirapov D.S., Baumjohann W. A new method for generating instantaneous ionospheric conductivity models using ground-based magnetic data. Planet. Space Sci. 1986, vol. 34, no. 8, pp. 713-722. DOI: 10.1016/00320633(86)90125-x.

Mishin V.M., Mishin V.V., Lunyushkin S.B., Wang J.Y., Moiseev A.V. 27 August 2001 substorm: Preonset phenomena, two main onsets, field-aligned current systems, and plasma flow channels in the ionosphere and in the magnetosphere. J. Geophys. Res.: Space Phys. 2017, vol. 122, no. 5, pp. 4988-5007. DOI: 10.1002/2017ja023915.

Newell P.T., Liou K., Zhang Y., Sotirelis T., Paxton L.J., Mitchell E.J. OVATION Prime-2013: Extension of auroral precipitation model to higher disturbance levels. Space Weather. 2014, vol. 12, no. 6, pp. 368-379. DOI: 10.1002/2014sw001056.

Reiff P.H. Models of auroral-zone conductances. Magnetospheric Currents. Ed. by T.A. Potemra, Washington, DC, AGU, 1984, pp. 180-191. DOI: 10.1029/GM028p0180.

Russell C.T., McPherron R.L. The magnetotail and substorms. Space Sci Rev. 1973, vol. 15, no. 2-3, pp. 205-266. DOI: $10.1007 /$ bf00169321.

Shirapov D.S., Mishin V.M., Bazarzhapov A.D., Saifudinova T.I. Adapted dynamic model of ionospheric conductivity. Geomagnetism and Aeronomy. 2000, vol. 40, no. 4, pp. 471-475.

Shukhtina M.A., Gordeev E.I., Sergeev V.A., Tsyganenko N.A., Clausen L.B.N., Milan S.E. Magnetotail magnetic flux monitoring based on simultaneous solar wind and magnetotail observations. J. Geophys. Res.: Space Phys. 2016, vol. 121, no. 9, pp. 8821-8839. DOI: 10.1002/2016ja022911.

Sotirelis T., Newell P.T. Boundary-oriented electron precipitation model. J. Geophys. Res. 2000, vol. 105, no. A8, pp. 18655-18673. DOI: 10.1029/1999ja000269.

Sugiura M. A fundamental magnetosphere-ionosphere coupling mode involving field-aligned currents as deduced from DE-2 observations. Geophys. Res. Lett. 1984, vol. 11, no. 9, pp. 877-880. DOI: 10.1029/GL011i009p00877.

Sun W., Lee L.C., Kamide Y., Akasofu S.I. An improve-ment of the Kamide-Richmond-Matsushita scheme for the estimation of the three-dimensional current system. J. Geophys. Res. 1985, vol. 90, no. A7, pp. 6469-6474. DOI: 10.1029/ JA090iA07p06469.

Troshichev O.A., Shishkina E.M., Lu G., Richmond A.D. Relationship of the ionospheric convection reversal to the hard auroral precipitation boundary. J. Geophys. Res. 1996, vol. 101, no. A7, pp. 15423-15432. DOI: 10.1029/96ja01192.

Vasyliūnas V.M. Mathematical Models of Magnetospheric Convection and its Coupling to the Ionosphere. Particles and Fields in the Magnetosphere. Ed. by B.M. McCormac, Springer Netherlands, 1970, pp. 60-71. DOI: 10.1007/978-94-010-3284-1_6.

Vorobjev V.G., Yagodkina O.I., Katkalov Y.V. Auroral Precipitation Model and its applications to ionospheric and magnetospheric studies. J. Atmos. Solar- Terr. Phys. 2013, vol. 102, pp. 157-171. DOI: 10.1016/j.jastp.2013.05.007.

Winningham J.D., Heikkila W.J. Polar cap auroral electron fluxes observed with Isis 1. J. Geophys. Res. 1974, vol. 79, no. 7, pp. 949-957. DOI: 10.1029/JA079i007p00949.

URL: http://supermag.jhuapl.edu (accessed June 2, 2018). 2018).

URL: http://vt.superdarn.org/tiki-index.php (accessed June 2,

How to cite this article.

Lunyushkin S.B., Penskikh Yu.V. Diagnostics of the auroral oval boundaries on the basis of the magnetogram inversion technique. SolarTerrestrial Physics. 2019. Vol. 5. Iss. 2. P. 88-100. DOI: 10.12737/stp51201913 